\title{
EVALUATION OF THE EFFECT OF ANAESTHETIC TECHNIQUES ON SURVIVAL AFTER INTRACRANIAL SURGERY FOR RUPTURED ANEURYSMS
}

\author{
Brian M. Marshall, M.D., F.R.C.P.(c), W. M. LougheEd, M.D., F.R.C.s.(c), \\ AND R. A. GoRDON, M.D., F.R.C.P.(C), F.F.A.R.C.S. ${ }^{\circ}$
}

THREe SIGNIFICANTLY DIFFERENT TECHNIQUES of general anaesthesia have been used at the Toronto General Hospital in conjunction with the surgical management of ruptured intracranial aneurysms since the initial case in 1954. This survey compares the effect of the different anaesthetic methods with respect to postoperative mortality. The results are analysed statistically and the possible relationships between anaesthesia and aneurysm mortality are discussed.

\section{Material}

The 401 patients presented in this series comprise all of the patients anaesthetized for intracranial surgery for ruptured intracranial aneurysms in the Department of Neurosurgery at the Toronto General Hospital from the initial case in May 1954 until December 1966. On admission the cases were graded $\mathrm{I}$ to $\mathrm{V}$ according to the classification reported by Botterell, Lougheed, Scott, and Vandewater. ${ }^{1}$ Those patients in grade V (eight cases) who were moribund, and who therefore received resuscitative measures only, are not included in this series. It could not be considered that these patients had any treatment which could be categorized as general anaesthesia. The total number of cases in each site and grade are outlined in Table I. The ages of the patients range from the second to the seventh decade, with 136 patients over fifty years.

TABLE 1

\begin{tabular}{lcccc}
\hline \hline & $\begin{array}{c}\text { Internal } \\
\text { carotid } \\
\text { artery }\end{array}$ & $\begin{array}{c}\text { Anterior } \\
\text { communications, } \\
\text { anterior } \\
\text { cerebral }\end{array}$ & $\begin{array}{c}\text { Middle } \\
\text { cerebral }\end{array}$ & Total \\
\hline Grade I & 53 & 37 & 20 & 110 \\
Grade II & 67 & 39 & 28 & 134 \\
Grade III & 47 & 41 & 29 & 117 \\
Grade IV & 13 & 9 & 18 & 40 \\
Total & 180 & 126 & 95 & 401 \\
\hline
\end{tabular}

\section{Methods of ANaEsthesia}

The initial method of anaesthesia was outlined by Vandewater, ${ }^{2}$ with modifications discussed two years later. ${ }^{3}$ The introduction of new agents and also the

${ }^{\circ}$ Departments of Anaesthesia and Neurosurgery, University of Toronto and Toronto General Hospital. 
adoption of various methods of obtaining decreased intracranial pressure during general anaesthesia resulted in subsequent changes in the anaesthetic technique. The techniques and agents used fall into four broad groups, outlined in Table II.

TABLE II

\begin{tabular}{lccccc}
\hline & $\begin{array}{c}\text { Group I: } \\
\text { nitrous oxide, } \\
\text { trichlorethylene, } \\
\text { lytic cocktail, } \\
\text { spontaneous } \\
\text { respiration }\end{array}$ & $\begin{array}{c}\text { Group II: } \\
\text { nitrous oxide, } \\
\text { halothane, } \\
\text { spontaneous } \\
\text { respiration }\end{array}$ & $\begin{array}{c}\text { Group III: } \\
\text { nitrous oxide, } \\
\text { halothane, } \\
\text { relaxant, } \\
\text { controlled } \\
\text { ventilation }\end{array}$ & $\begin{array}{c}\text { Group IV: } \\
\text { miscellaneous }\end{array}$ & Total \\
\hline Grade I & 24 & 35 & 39 & 12 & 110 \\
Grade II & 24 & 42 & 57 & 11 & 134 \\
Grade III & 27 & 39 & 40 & 11 & 117 \\
Grade IV & 14 & 15 & 7 & 4 & 40 \\
Total & 89 & 131 & 143 & 38 & 401 \\
\hline
\end{tabular}

All patients in groups I, II, and III and many in group IV received moderate hypothermia $\left(28^{\circ}\right.$ to $30^{\circ} \mathrm{C}$.), induced by a surface cooling technique. In group I, 89 patients in all, the patients had premedication with "lytic cocktail," chlorpromazine, demerol, and promethazine. Induction was carried out with thiopentone or an intravenous infusion of "lytic cocktail." The anaesthetic maintenance was continued with nitrous oxide and trichlorethylene and further amounts of chlorpromazine or demerol. In this group respirations were spontaneous.

In group II-131 patients-halothane was the major anaesthetic agent. Preoperative sedation was rarely used, and supplementary drugs were rarely given during the general anaesthetic. In this group also respirations were spontaneous. Group III, 143 patients, differed from group II only in that controlled ventilation was employed. There was some overlapping in time between groups II and III, but both groups II and III followed group I chronologically. The patients in group IV, 38 patients altogether, comprise all those who were excluded from the other groups because the anaesthetic technique differed in one or more major respects from that used in the initial three groups. They are not used for any specific comparison, but added to the total of 401 patients to establish an accurate total mortality.

With groups I, II, and III two specific comparisons of the effects of different techniques of general anaesthesia upon postoperative mortality may be made. The factor of moderate hypothermia is present in each group, and therefore should have no effect upon the comparisons. In the first pair, group I and group II, the anaesthetic technique of hypothermia, heavy preoperative sedation with "lytic cocktail," and general anaesthesia with trichlorethylene and narcotic supplement, is compared with hypothermia and general anaesthesia using halothane alone. A comparison of group II and group III should indicate the effect upon patients in this series resulting from the addition of controlled ventilation to general anaesthesia with halothane. 


\section{Results}

The results are tabulated as deaths or survivals. The classification of certain cases differs from the usual surgical mortality classification because the prime interest is in the effect of general anaesthesia upon mortality, not the effect of surgery upon mortality. In this series, a patient who has a "rebleed" two weeks or more after the operation, from either the same or another aneurysm, is included in the survivor group. Deaths from a "rebleed" within two weeks of the initial operation are included in the mortality group.

Table III shows the percentage mortality in each group and also in the overall series. The difference between the three proportions was checked by the chisquared test. No significant difference was found between the three proportions $(p>.05)$. The difference between each pair was also checked by the chi-squared test and no significant differences were found in any of the three cases. On a statistical basis, therefore, there is no difference in mortality between three similar groups of cases in which there were specific differences in anaesthetic agents or techniques.

TABLE III

\begin{tabular}{|c|c|c|c|c|c|c|c|c|c|c|}
\hline & \multicolumn{2}{|c|}{ Group I } & \multicolumn{2}{|c|}{ Group II } & \multicolumn{2}{|c|}{ Group III } & \multicolumn{2}{|c|}{ Group IV } & \multicolumn{2}{|c|}{ Total } \\
\hline & death & survival & death & survival & death & survival & death & survive & death & survival \\
\hline Grade I & 1 & 23 & 0 & 35 & 2 & 37 & 0 & 12 & 3 & 107 \\
\hline Grade II & 4 & 20 & 6 & 36 & 11 & 46 & 0 & 11 & 21 & 113 \\
\hline Grade III & 8 & 19 & 12 & 27 & 12 & 28 & 3 & 8 & 35 & 82 \\
\hline Grade IV & 8 & 6 & 7 & 8 & 3 & 4 & 2 & 2 & 20 & 20 \\
\hline Total & 21 & 68 & 25 & 106 & 28 & 115 & 5 & 33 & 79 & 322 \\
\hline Mortality (\%) & \multicolumn{2}{|c|}{23.6} & \multicolumn{2}{|r|}{19} & \multicolumn{2}{|c|}{19.5} & \multicolumn{2}{|r|}{13} & \multicolumn{2}{|c|}{18.4} \\
\hline
\end{tabular}

\section{Discussion}

Between groups I and II, the only significant difference in anaesthetic technique is in the agents used. In the later group, halothane was substituted for trichlorethylene and "lytic cocktail." D. G. McDowall reports an increase in cerebral blood flow in general anaesthesia with halothane, ${ }^{4}$ and McDowall, Harper, and Jacobson report no increase in cerebral blood flow with trichlorethylene anaesthesia. $^{5}$ On the basis of this experimental data, it would appear that halothane was preferable to trichlorethylene in the surgical treatment of ruptured intracranial aneurysms. Analysis of our clinical results, however, does not show any apparent difference between the two agents.

The work of Allcock and Drake suggests the possible implication of hyperventilation as a factor in the production of cerebrovascular spasm. ${ }^{6}$ Hyperventilation with resulting hypocarbia is reported to increase cerebrovascular resistance and reduce cerebral blood flow. It is almost impossible to carry on general anaesthesia with controlled ventilation without some degree of hypocarbia. On 
this basis, therefore, it would appear that the patients in group III would be more subject to decrease in cerebral blood flow than those in group II. On the basis of the clinical results, however, this factor did not cause a significant change in the overall mortality.

M. R. Crompton ${ }^{7}$ and S. A. Schneck ${ }^{8}$ present analyses of studies of cerebral infarction following surgery for ruptured intracranial aneurysms with special reference to the pathogenesis of the infarct. It is the conclusion of both authors that direct surgical attack on the aneurysm is one contributing factor in the production of cerebral infarction. The possible role of the effects of general anaesthesia as an additional contributing factor was not discussed.

In the three groups of patients in this series, we have been able to study two pairs of techniques. On theoretical grounds, group II should be better than group I in the first pair. In the second pair, group III should be worse than group II. Statistical analysis has, however, shown no significant difference in the two groups, nor has any difference been shown between any one group and the total mortality figures.

In this series there is no large group treated without hypothermia to compare with the other groups, and so no evaluation can be made of the effects of hypothermia in conjunction with general anaesthesia. Series reported by Hillings, ${ }^{9}$ and by Bozza Marrubini, Visca, Tritola, and Signorini, ${ }^{10}$ report no increase in mortality resulting from the use of moderate hypothermia in the surgical management of intracranial aneurysms. Maspes and Marini, ${ }^{11}$ discussing the surgical treatment of ruptured intracranial aneurysms by a direct surgical attack upon the aneurysm with temporary occlusion, state: "The data shows that the operative use of moderate hypothermia does not result in additional risk even in old or hypertensive patients." Our impression agrees with the conclusions of these authors. We have not found moderate hypothermia per se a factor contributing to operative or postoperative mortality. We therefore feel justified in stating that moderate hypothermia should not alter the comparisons of the anaesthetic techniques which we have made.

There are different possible conclusions which may be made from this clinical series, when considered along with the experimental and postmortem studies mentioned:

1. Different anaesthetic techniques affect the postoperative mortality equally, either not at all, or beneficially, or adversely.

2. Any effects of general anaesthesia are transient, and do not produce any permanent change even in the pathological situation of ruptured intracranial aneurysm.

3. Some effects of general anaesthesia (such as decreasing cerebral oxygen requirement) protect the brain from possible damage resulting from changes in cerebral blood flow.

4. The ruptured aneurysm with its sequelae has such a powerful effect upon the cerebral vascular tree that any effects which anaesthetic agents or techniques might produce are inconsequential and can neither add to nor alleviate the problem. 


\section{SUMMARY}

A comparative evaluation has been made of the effects of different anaesthetic agents and techniques upon the mortality of patients undergoing intracranial surgery for ruptured intracranial aneurysms. No statistically significant difference was noted when comparing groups in which halothane or trichlorethylene was the main anaesthetic agent. Neither was there any difference in mortality in groups in which halothane was used with or without controlled ventilation. It is concluded that variation in agent or method of general anaesthesia, which should on theoretical grounds result in differences in cerebral blood flow, has not affected postoperative mortality rates either adversely or beneficially.

\section{RÉSUMÉ}

On a fait une étude comparée de l'effet de différents agents et techniques anesthésiques sur la mortalité de malades opérés pour rupture d'anévrysmes intracrâniens. On n'a pas noté de différences sensibles dans les groupes où l'halothane ou le trichloréthylène étaient utilisés comme agent anesthésique principal. On n’a pas non plus trouvé de différence de mortalité, que l'halothane aît été utilisé avec ou sans ventilation contrôlée. En conclusion, le changement d'agent ou de technique, qui théoriquement devrait faire varier la circulation cérébrale, n’a pas influencé le taux de mortalité post-opératoire, ni en plus ni en moins.

\section{REFERENCES}

1. Bottereld, E. H.; Lougheed, W. M.; Scott, J. W.; \& Vandewater, S. L. Hypothermia and Interruption of Carotid, or Carotid and Vertebral Circulation, in the Surgical Management of Intracranial Aneurysms. J. Neurosurg. 19: 1 (1956).

2. Vandewater, S. L.; Bottereld, E. H.; \& LougheEd, W. M. A Method of Anaesthesia and Hypothermia in Cerebral Vascular Surgery, Canad. Anaesth. Soc. J. 2: 314 (1955).

3. Vandewater, S. L.; Lougheed, W. M.; Scotr, J. W.; \& Botterell, E. H. Some Observations with the Use of Hypothermia in Neurosurgery. Anaesth. \& Analg. 37: 12 (1958).

4. McDowali, D. G. Effects of General Anaesthesia on Cerebral Blood Flow and Cerebral Metabolism. Brit. J. Anaesth. 37: 236 (1965).

5. McDowall, D. G.; Harper, A. M.; \& Jacobson, I. Cerebral Blood Flow during Trichlorethylene Anaesthesia: A Comparison with Halothane. Brit. J. Anaesth. 36: 11 (1964).

6. Allcock, J. M. \& Drake, C. G. Ruptured Intracranial Aneurysms: The Role of Arterial Spasm. J. Neurosurg. 25: 21 (1965).

7. Crompton, M. R. Pathogenesis of Cerebral Infarction Following the Rupture of Cerebral Bury Aneurysms. Brain. 87: 491 (1964).

8. SCHNeCK, S. A. On the Relationship between Ruptured Intracranial Aneurysms and Cerebral Infarction. Neurology. 14: 691 (1964).

9. Hillings, Pameal M. Controlled Hypothermia: Recent Developments in Neurosurgery. Brit. M. J. 2: 346 (1958).

10. Bozza Marrubini; Visca, A.; Trutola, L.; \& Signoroni, G. Methods of Moderate Hypothermia in Neuroanaesthesia: Clinical Observations on Physiological and Metábolic Changes. Acta. Neurosurg. Supp. XII, p. 71: Hypothermia in Neurosurgery.

11. MAspes, P. E. \& MARINI, G. Intracranial Aneurysms: Results of Direct Surgical Treatment with Special Reference to the Use of Moderate Hypothermia and Circulatory Arrest. J. Neurosurg. 21: 284 (1964). 